\title{
MANFAAT TERAPI MASASE FRIRAGE DAN STRETCHING DALAM PENANGANAN CEDERA PADA ATLET OLAHRAGA BELADIRI
}

\author{
Oleh: Ali Satia Graha \\ Jurusan Pendidikan Kesehatan dan Rekreasi FIK-UNY
}

\begin{abstract}
Abstrak
Prestasi puncak atlet, khususnya cabang beladiri tidak terlepas dari peranan penerapan IPTEK olahraga dalam pembinaan prestasi agar menciptakan atlet beladiri yang berprestasi. Atlet beladiri yang berprestasi banyak berasal dari daerah yang memiliki cabang olahraga yang diunggulkan untuk mengikuti event kejuaraan nasional maupun internasional seperti pada Pekan Olahraga Mahasiswa Nasional (POMNAS), Pekan Olahraga Nasional (PON), Universiade, Asian Games, Sea Games dan Olimpiade. Namun demikian, tujuan untuk mendapat medali sering terhambat oleh cedera, baik dalam proses latihan maupun saat bertanding.

Berdasarkan keadaan tersebut, akhir-akhir ini berbagai jenis terapi masase telah diterapkan untuk meningkatakan prestasi atlet beladiri dengan tujuan mengurangi tingkat cedera ringan, di antaranya terapi masase frirage dan stretching. Manfaat masase frirage dapat membantu mempelancar peredaran darah, mengurangi rasa nyeri, dan membantu memposisikan pergeseran sendi akibat keseleo, sedangkan stretching dapat membantu otot tetap fleksibel serta mengurangi kekakuan dan kontraksi. Manfaat dari kedua terapi tersebut sangat membantu atlet beladiri dalam mengatasi gangguan cederanya, sehingga diharapkan dapat mencapai prestasi tinggi dalam setiap kejuaraan.
\end{abstract}

Kata kunci: masase frirage, stretching, cedera dan olahraga beladiri

Prestasi puncak atlet, khususnya cabang beladiri tidak terlepas dari peranan penerapan IPTEK olahraga dalam pembinaan prestasi agar menciptakan atlet beladiri yang berprestasi. Atlet beladiri yang berprestasi banyak berasal dari daerah yang memiliki cabang olahraga yang diunggulkan untuk mengikuti event kejuaraan nasional maupun internasional seperti pada Pekan Olahraga Mahasiswa Nasional (POMNAS), Pekan Olahraga Nasional (PON), Universiade, ASIAN Games, Sea Games, dan Olimpiade. Akan tetapi atlet cabang beladiri di tiap daerah tidak banyak bisa mendapat medali yang dipertandingkan dalam event tersebut di atas karena mengalami cedera akibat proses latihan maupun saat bertanding.

Dari hasil pengamatan di Physical Therapy Clinic FIK UNY yang membantu atlet mendapatkan terapi, terungkap bahwa tidak maksimalnya prestasi atlet cabang beladiri disebabkan saat melakukan latihan dan bertanding, atlet beladiri selalu mengalami cedera 


\section{MEDIKORA Vol. VIII, No 2 April 2012}

bagian anggota gerak tubuh seperti engkel, lutut, panggul, jari tangan, pergelangan tangan, siku, dan bahu. Hal ini kemungkinan diakibatkan dari proses latihan atau bertanding sehingga menimbulkan cedera, tetapi tidak cepat mendapatkan penanganan yang tepat sebagai upaya memulihkan cedera tersebut.

Berdasarkan keadaan tersebut akhir-akhir ini berbagai jenis terapi masase telah diterapkan untuk meningkatkan prestasi atlet dan mengurangi tingkat cedera ringan, antara lain: terapi masase frirage dan stretching. Tingkat cedera yang tinggi apabila tidak segera mendapatkan penanganan yang tepat maka akan timbul kecacatan dan penurunan prestasi atlet tersebut. Oleh karena itu, para masseur yang bernaung pada tenaga keolahragaan yang bekerjasama dengan tim medis, gizi, maupun psikolog akan sangat membantu dalam upaya penanganan pada cedera ringan. Jadi dari pernyataan di atas, terapi masase frirage dan stretching perlu diterapkan untuk membantu dan meningkatkan prestasi unggulan atlet cabang beladiri sehingga bisa mendapatkan medali emas dalam setiap event kejuaraan.

\section{MASASE FRIRAGE}

Masase frirage berasal dari kata, masase yang artinya pijatan dan frirage yaitu gabungan teknik masase atau manipulasi dari friction (gerusan) dan efflurage (gosokan) yang dilakukan secara bersamaan dalam melakukan pijatan. Masase frirage ini, sebagai salah satu ilmu pengetahuan terapan yang termasuk dalam bidang terapi dan rehabilitasi, baik untuk kepentingan sport medicine, pendidikan kesehatan maupun pengobatan kedokteran timur (pengobatan alternatif) yang dapat bermanfaat untuk membantu penyembuhan setelah penanganan medis maupun sebelum penanganan medis sebagai salah satu pencegahan dan perawatan tubuh dari cedera (Ali Satia Graha dan Bambang Priyonoadi, 2009). Teknik masase (masase frirage) pada rehabilitasi cedera yang digunakan yaitu teknik masase berupa gerusan (friction), gosokan (effleurage) menggunakan ibu jari dan penarikan (traksi) serta pengembalian sendi pada posisinya (reposisi).

Manfaat dari masing-masing teknik masase frirage secara fisiologis pada otot manusia antara lain: (1) Gerusan (friction) tujuannya yaitu merangsang serabut saraf dan otot-otot yang terletak di dalam, jauh dari permukaan tubuh. Di samping itu gerakan gerusan yang berupa gerak-gerak melingkar seperti spiral akan membantu menghancurkan myoglosis, yaitu timbunan dari sisa-sisa pembakaran yang terdapat pada otot-otot dan menyebabkan pengerasan serabut-serabut otot (Tjiptosoeroso, 1983); (2) Gosokan (effleurage) caranya adalah dengan meng-gunakan ibu jari untuk mengosok daerah tubuh yang mengalami kekakuan otot. Tujuannya adalah untuk memperlancar peredaran darah dan cairan getah 


\section{MEDIKORA Vol. VIII, No 2 April 2012}

bening (cairan limfe), sehingga darah yang mengalir pada pembuluh darah balik (vena) dapat cepat kembali ke jantung. Oleh karenanya gerakan effleurage ini harus selalu menuju ke arah jantung, sebab jantung adalah pusat peredaran darah. Darah yang mengalir cepat dari vena kembali ke jantung akan mempercepat pula proses pembuangan sisa-sisa pembakaran sebab darah vena membawa sisa pembakaran yang berasal dari seluruh tubuh untuk dibuang melalui alat-alat pembuangan (Tjiptosoeroso, 1983); (3) Tarikan (traksi) caranya adalah dengan menarik bagian anggota gerak tubuh yang mengalami cedera, khususnya pada sendi ke posisi semula (Ali Satia Graha, 2009); (4) Mengembalikan sendi pada posisinya (reposisi) caranya adalah waktu penarikan (traksi) pada bagian anggota gerak tubuh yang mengalami cedera khususnya pada bagian sendi dilakukan pemutaran atau penekanan agar sendi kembali pada posisi semula (Ali Satia Graha, 2009).

\section{STRECHING}

Stretching atau peregangan lebih dikenal masyarakat luas dengan istilah pemanasan (warm up). Stretching adalah bentuk dari penguluran atau peregangan otot-otot di setiap anggota badan agar dalam setiap melakukan olahraga terdapat kesiapan serta untuk mengurangi risiko cedera yang dapat terjadi (Ratal Ws, 1979), sedangkan menurut Panggung Sutapa (2007) stretching juga merupakan suatu proses yang bertujuan mengadakan perubahan-perubahan fisiologis dalam tubuh dan menyiapkan organ-organ dalam untuk menghadapi aktivitas-aktivitas yang akan dilakukan. Menurut Taylor (2002), ada tiga jenis teknik peregangan yang dapat dilakukan, yaitu: (1) teknik peregangan statis, (2) teknik balistis, (3) teknik PNF (proprioceptive neuromuscular facilitation).

Peregangan statis merupakan peregangan yang paling banyak dipergunakan. Peregangan ini dilakukan secara perlahan-lahan sampai pada titik resistensi atau sampai terasa sedikit sakit, kemudian bertahan pada posisi meregang selama beberapa saat. Latihan peregangan tersebut kemudian diulangi sampai beberapa kali untuk tiap kelompok otot.

Teknik peregangan balistis merupakan teknik peregangan dengan gerakan yang lebih kuat dan menggunakan gerakan-gerakan bouncing (gerakan seperti mengayun) secara berulang-ulang. Teknik ini mempunyai potensi terjadi cedera yang cukup besar, sehingga masyarakat awam tidak dianjurkan menggunakan teknik ini.

Teknik PNF (proprioceptive neuromuscular facilitation) banyak digunakan oleh para dokter dan ahli terapi fisik dalam memeriksa dan mempertimbangkan respon fisiologis dari sistem saraf, otot, persendian dan tendon. Teknik ini merupakan teknik peregangan paling efektif. Namun teknik PNF ini tidak banyak dikenal oleh masyarakat luas, selain lebih sulit 


\section{MEDIKORA Vol. VIII, No 2 April 2012}

dalam melakukannya, teknik ini membutuhkan partner atau teman latihan (dengan kata lain tidak dapat dilakukan sendiri).

\section{CEDERA}

Cedera merupakan rusaknya jaringan lunak atau keras disebabkan adanya kesalahan teknis, benturan atau aktivitas fisik yang melebihi batas beban latihan yang dapat menimbulkan rasa sakit akibat dari kelebihan latihan melalui pembebanan latihan yang terlalu berat sehingga otot dan tulang tidak lagi dalam keadaan anatomis. Cedera dapat terjadi pada aktivitas apapun dengan waktu yang relatif singkat baik secara sadar maupun tidak disadari.

Macam-macam cedera yang terjadi dalam aktivitas sehari-hari maupun dalam berolahraga dibagi menjadi 2, yaitu cedera ringan dan cedera berat (Ali Satia Graha dan Bambang Priyonoadi, 2009), yang dijabarkan sebagai berikut; (1) Cedera ringan yaitu cedera yang terjadi karena tidak ada kerusakan yang berarti pada jaringan tubuh, misalnya kekakuan otot dan kelelahan. Cedera ringan tidak memerlukan penanganan khusus, biasanya dapat sembuh sendiri setelah istirahat; (2) Cedera berat yaitu cedera serius pada jaringan tubuh dan memerlukan penanganan khusus dari medis, misalnya robeknya otot, tendon, ligamen atau patah tulang.

Gejala yang timbul akibat cedera dapat berupa peradangan. Seperti yang diungkapkan Wara Kushartanti (2007), peradangan merupakan mekanisme mobilisasi sistem pertahanan tubuh dan reaksi fisiologis dari jaringan rusak baik akibat tekanan mekanis, kimiawi, panas, dingin dan invasi bakteri. Radang mempunyai tujuan memproteksi area yang cedera dan melayani proses penyembuhan. Diperjelas oleh Ali Satia Graha dan Bambang Priyonoadi (2009), tanda-tanda peradangan pada cedera jaringan tubuh yaitu; (1) Kalor atau panas karena meningkatnya aliran darah ke daerah yang mengalami cedera; (2) Tumor atau bengkak disebabkan adanya penumpukan cairan pada daerah sekitar jaringan yang cedera; (3) Rubor atau merah pada bagian cedera karena adanya pendarahan.; (4) Dolor atau rasa nyeri, karena terjadi penekanan pada saraf akibat penekanan baik otot maupun tulang; (5) Functiolaesa (penurunan fungsi), karena kerusakan yang diakibatkan cedera berat.

Berdasarkan tanda-tanda peradangan di atas, maka akan berdampak pada ROM atau luas cakupan pergerakan sendi. Sendi yang sering mengalami cedera ringan pada atlet beladiri yaitu engkel, lutut, panggul, pergelangan tangan, siku, dan bahu. Seperti yang diuraikan dibawah ini:

1. Cedera Engkel 


\section{MEDIKORA Vol. VIII, No 2 April 2012}

Cedera engkel merupakan salah satu cedera akut yang sering dialami atlet. Cedera ini dapat mempengaruhi pergelangan kaki dan dapat merusak bagian luar ligamen. Hal ini terjadi pada saat kaki melakukan belokan atau memutar pada tungkai kaki, meregangkan pergelangan pada titik dimana akan merobek ligamen atau dislokasi pada tulang persendian pergelangan kaki (Taylor, 2002). Seperti dapat dilihat pada gambar berikut:

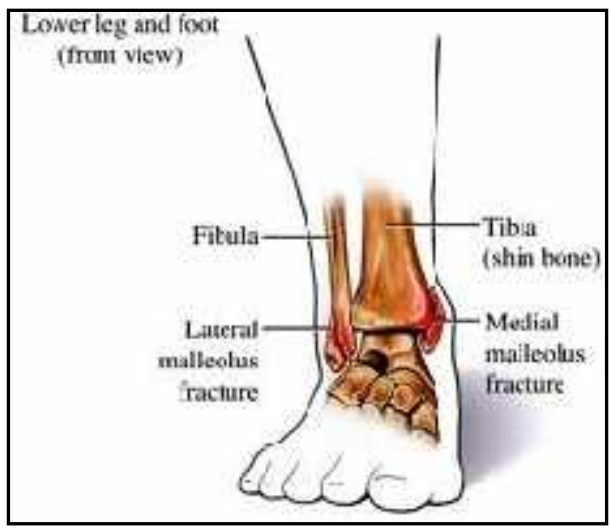

Gambar 1. Cedera engkel

(Sumber:http://www.blog.myfitnessyear.com hari selasa tanggal 5-4-2011 jam11:49)

2. Cedera lutut

Sendi lutut merupakan sendi yang paling besar pada tubuh manusia. Sendi ini tersusun dari empat tulang dan ikatan ligamen serta otot-otot. Sendi lutut dibentuk oleh 3 (tiga) tulang yaitu femur, tibia, dan patela. Pergerakan utama dari sendi lutut terjadi antara tulang femur, patela dan tibia, dan setiap bagian tulang yang berhubungan tersebut dibungkus oleh kartilago artikular yang keras, namun halus dan didesain untuk mengurangi risiko terjadinya cedera antar-tulang, serta tulang patela terletak pada tulang tibia bagian fossa intercondylar (Martini, 2001). Macam-macam cedera lutut yang terjadi pada kebanyakan orang akibat aktivitas fisik antara lain: tendinitis patellar, patella chondromalasia, bursitis anserinus pers, sindrom iliotibial band, knee sprain (keseleo lutut), cedera meniskal, tendinitis popliteal, sindrom plica lutut, pergeseran patella, malalignment mekanisme ektensor dan cedera ligament krusiat anterior (Taylor, 2004), sedangkan yang sering terjadi pada atlet beladiri, salah satunya atlet beladiri pencak silat putri dari hasil penelitian, Yanuita (2011), jenis cedera lutut yang sering dialami oleh pesilat putri, adalah cedera Knee Sprain (keseleo lutut). Cedera ini diakibatkan karena latihan fisik yang berlebih seperti latihan yang menggunakan gerakan lutut, diantaranya gerakan melompat, meloncat, dan menendang. Selain permasalahan di atas saat bertanding 


\section{MEDIKORA Vol. VIII, No 2 April 2012}

pesilat putri sering mengalami cedera lutut dikarenakan terkena teknik sapuan, guntingan, dan bantingan dari lawan.

3. Cedera Panggul

Panggul adalah sendi yang berbentuk sebuah bola dan lekukan yang berbentuk mangkuk dan terbentuk dari sambungan antara tulang femur dan pelvis. Menurut Martini (2001), sakit panggul biasanya berasal dari trochanterik atau bursitis pada panggul. Bursitis adalah keadaan di mana bursa (kantong yang berisi cairan synovial) mengalami peradangan atau teriritasi sehingga akan memproduksi cairan synovial tambahan dan meningkatkan tekanan pada bursa. Cairan yang lebih banyak dan adanya tekanan yang bertambah pada kantong sebagai akibat adanya pembengkakan dapat menimbulkan rasa sakit atau nyeri. Selain bursitis, panggul bisa juga mengalami fraktur (patah atau retak) dan dislokasi (salah letak) pada sendi. Seperti dapat dilihat pada gambar di bawah ini:

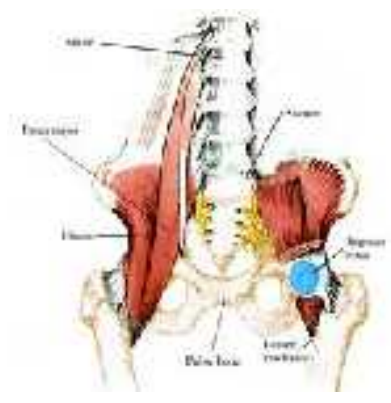

(a)

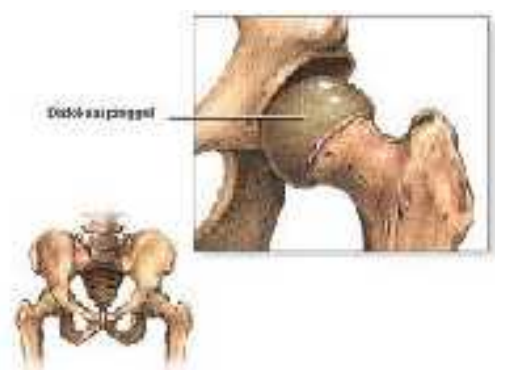

(b)

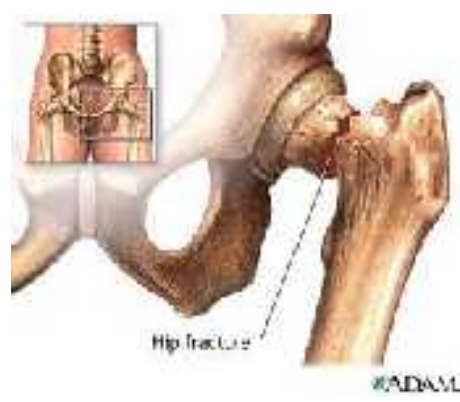

(c)

Gambar. 2: (a) bursitis, (b) dislokasi dan (c) fraktur panggul $22: 15)$

(Sumber:http://www.footclinic.wordpress.com hari senin tanggal 04-04-2011 jam

\section{Cedera pergelangan tangan}

Cedera yang sering terjadi adalah tendo sinovitis dari otot-otot ekstensor lengan bawah dan mengakibatkan pergelangan tangan sakit. Macam-macam cedera pergelangan tangan sebagai berikut (Ali Satia Graha dan Bambang Priyonoadi, 2009):

a. Cedera pergelangan tangan sering dijumpai pada daerah punggung tangan yang disebut ganglion yang diduga akibat pembesaran pembungkus tendo dan berisi lendir.

b. Cedera pergelangan tangan throwers wrist akibat hiperekstensi pada otot lengan.

Jadi ketika pergelangan tangan mengalami cedera maka yang akan timbul di situ adalah rasa nyeri dan peradangan. Proses rasa nyeri dan peradangan yang terjadi pada 


\section{MEDIKORA Vol. VIII, No 2 April 2012}

sendi pergelangan tangan, akan diikuti rasa nyeri dan peradangan pada otot-otot di sekitar pergelangan tangan tersebut, seperti dapat dilihat pada gambar berikut:

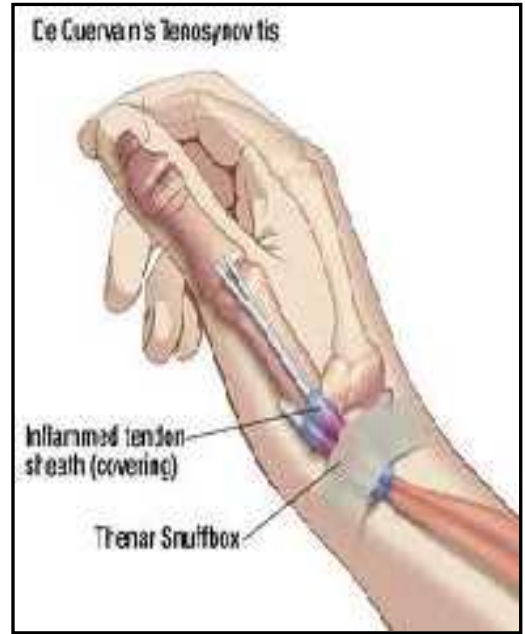

Gambar 3. inflamasi tendo sheath

(Sumber:http://www.blog.myfitnessyear.com hari selasa tanggal 5-4-2011 jam11:45)

5. Cedera Siku

Elbow injuries adalah cedera yang menyebabkan rasa nyeri pada siku yang menjalar kearah bawah. Biasanya terjadi karena karena gangguan neuromuskuloskeletal, yaitu komponen lunak yang terdiri dari ligamenum, tendo, kapsul sendi, jaringan ikat sendi, serabut saraf perifer dan pembuluh darah (Ali Satia Graha dan Bambang Priyonoadi, 2009). Macam-macam cedera yang sering terjadi pada siku yaitu:

\section{a. Medial Epicondylitis}

Medial epicondylitis sering terjadi pada siku bagian dalam epicondylus medialis humeri (Ali Satia Graha dan Bambang Priyonoadi, 2009). Trauma pada medial epicondylitis terjadi pada origo otot-otot yang melakukan fleksi lengan bawah. Penyebab terjadinya medial epicondylitis disebabkan oleh menekuknya pergelangan tangan ke arah telapak tangan karena adanya tekanan yang berlebihan. Menurut (Medicastore, 2010: 1) faktor-faktor yang menghasilkan tekanan seperti tersebut adalah sebagai berikut:

1) Otot bahu dan otot tangan yang lemah

2) Melakukan serve dengan tenaga yang luar biasa pada saat bermain tenis

3) Memukul bola yang berat dan basah 


\section{MEDIKORA Vol. VIII, No 2 April 2012}

4) Menggunakan raket yang terlalu berat atau tali senarnya terlalu tegang

5) Melempar bola

6) Melempar lembing

7) Membawa koper yang berat

Gejala yang terjadinya medial epicondylitis adalah nyeri dirasakan di sepanjang sikut pada sisi telapak tangan dan lengan bawah bagian dalam dan apabila melanjutkan latihan bisa menyebabkan tertariknya tendon dari tulang sehingga terjadi perdarahan (Medicastore, 2010).

Tanda dan gejala medial epicondylitis yang dikemukakan oleh Jowir (2009) adalah sebagai berikut:

1) Nyeri pada tulang yang letaknya agak di dalam pada sendi siku.

2) Kelemahan pada otot-otot pergelangan tangan.

3) Nyeri pada siku bagian dalam ketika menggenggam sesuatu yang keras

4) Nyeri pada saat dilakukan fleksi dengan diberikan tahanan

5) Nyeri saat pronasi

\section{b. Lateral Epicondylitis}

Lateral epicondylitis sering terjadi pada posisi luar siku. Cedera ini biasanya terjadi karena pukulan tangkisan yang bersifat terus menerus sehingga menyebabkan over use (Ali Satia Graha dan Bambang Priyonoadi, 2009). Adapun salah satu macam cedera siku dapat dilihat pada gambar berikut:

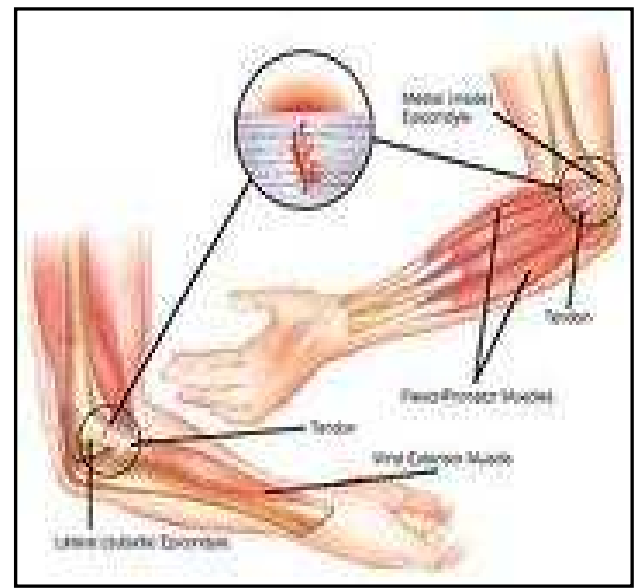

Gambar 4. Lateral epicondylitis

(Sumber:http://www.blog.myfitnessyear.com hari selasa tanggal 5-4-2011 jam11:53) 


\section{MEDIKORA Vol. VIII, No 2 April 2012}

6. Cedera Bahu

Cedera bahu sering disebabkan karena terlalu lelah dan akibat benturan atau body contact yang terjadi pada atlet saat latih tanding atau pertandingan. Macam-macam cedera bahu menurut Ali Satia Graha dan Bambang Priyonoadi (2009) adalah sebagai berikut:

a. Luksasio/subluksasio dari artikulasio humeri

Pada sendi bahu sering terjadi luksasio/subluksasio karena sifatnya globeida (kepala sendi yang masuk ke dalam mangkok sendi kurang dari separuhnya). Tandatanda luksasio antara lain: lengkung bahu hilang, tidak dapat digerak-gerakkan, lengan atas sedikit abduksi, lengan bawah sedikit supinasi.

b. Luksasio/subluksasio dari artikulasio akromio clavicularis

Sendi akromio clavicularis kerap kali mengalami cedera karena jatuh atau dipukul pada ujung bahu. Jika cedera ini terbatas pada robeknya ligamentum akromio clavicularis, maka terjadi subluksasio/dislokasi sebagian. Jika robekan pada ligamenum akromio clavicularis dan ligamenum coraco clavicularis, maka terjadi luksasio atau dislokasi total. Pada keadaan luksasio/subluksasio dari sendi ini, maka dapat kita raba terangkatnya ujung klavikulare bagian acromion lebih tinggi. Bila cedera sudah berlangsung lama, pembengkakan sudah terjadi, maka ujung klavikulare sukar teraba.

\section{c. Subdeltoid bursitis}

Sendi bahu dapat berfungsi dengan gerakannya yang halus karena adanya bursa subdeltoid dan bursa ini dapat meradang. Bursa mukosa subdeltoid ini memberi pelicin pada tendo yang berjalan pada atap bahu. Jika bursa ini cedera, maka akan sedikit membengkak dengan bertambahnya cairan sinovial dan pada gerakan terasa nyeri.

d. Strain dari otot-otot atap bahu (rotator cuff)

Rotator cuff dibentuk dengan bersatunya tendo-tendo atap bahu, tendo-tendo tersebut ialah: m. Supraspinalis, m. Infraspinatus, m. Teres minor, m. Subskapularis. Pada cedera bahu yang paling sering kena adalah tendo supraspinatus. Tanda-tanda cedera bahu adalah mengeluh nyeri di ujung bahu. Jika penderita menaikkan lengan kesamping setelah 45 derajat pertama, penderita mulai sakit, lebih-lebih setelah lengan melebihi 45 derajat, tetapi rasa sakit berkurang lagi setelah lewat 120 derajat.

Jadi dari uraian di atas tentang cedera yang terkena pada gerak sendi anggota tubuh sering terjadi pada atlet beladiri, baik saat berlatih maupun bertanding. Kondisi cedera yang terjadi pada atlet beladiri memerlukan penanganan secara cepat dengan mendapatkan 


\section{MEDIKORA Vol. VIII, No 2 April 2012}

penanganan dari medis ataupun terapis sesuai dengan jenis cedera yang di alami oleh atlet beladiri tersebut.

\section{OLAHRAGA BELADIRI}

Olahraga beladiri merupakan olahraga yang tidak terlepas dari body contact, sehingga akan terjadi cedera yang sangat tinggi. Beberapa cedera yang terjadi pada atlet beladiri antara lain: memar, robek, sprain, strain, fraktur, gegar otak, dan gangguan gerak sendi pada anggota tubuh baik ekstrimitas atas maupun bawah. Gangguan gerak sendi anggota tubuh yang dialami atlet beladiri antara lain: sendi engkel, sendi lutut, sendi panggul, sendi siku, sendi pergelangan tangan, dan sendi lainnya. Semua cedera tersebut membuat atlet bela diri tidak dapat berprestasi secara maksimal dan menjadi cacat yang permanen. Seperti yang terjadi pada cabang beladiri taekwondo, karate, pencaksilat, judo, wushu, tinju, gulat, kempo, tarung derajat, dan lain-lain. Atlet beladiri tersebut di atas yang mengalami cedera baik di saat latihan maupun bertanding memerlukan perhatian khusus dan penenganan secara khusus pula, baik medis maupun dari terapis yang berkompeten di bidangnya, sehingga penampilan atlet beladiri akan maksimal dalam mencapai prestasi yang diinginkannya.

\section{KESIMPULAN}

Manfaat terapi masase frirage dan stretching sangat diperlukan untuk atlet olahraga beladiri. Manfaat masase frirage dapat membantu mempelancar peredaran darah, mengurangi rasa nyeri dan membantu memposisikan pergeseran sendi akibat keseleo. Di sisi lain stretching dapat membantu otot tetap fleksibel dan mengurangi kekakuan, dan kontraksi. Manfaat dari kedua terapi tersebut sangat membantu atlet beladiri dalam mengurangi ganguan cederanya, sehingga dapat mencapai prestasi yang tinggi dalam setiap kejuaraan.

\section{DAFTAR PUSTAKA}

Ali Satia Graha. (2009). Pedoman dan Modul Terapi Masase Frirage Penatalaksanaan Terapi Masase dan Cedera Olahraga pada Lutut dan Engkel. Yogyakarta: Klinik Terapi Fisik UNY.

Ali Satia Graha dan Bambang Priyonoadi. (2009). Terapi Masase Frirage Penatalaksanaan Cedera pada Anggota Tubuh Bagian Atas. Yogyakarta: FIK UNY.

Antony Eko Raharjo. (2008). Usaha Pencegahan Cedera Pehoki Daerah Istimewa Yogyakarta. Skripsi. Yogyakarta: FIK UNY. 


\section{MEDIKORA Vol. VIII, No 2 April 2012}

B.M. Wara Kushartanti. (2007). Patofisiologi Cedera Olahraga. Makalah. Yogyakarta: Klinik Terapi Fisik FIK UNY.

Jowir. (2009) Fisioterapi Anda. Diakses dari http://seripayku.blogspot.com/cedra-padaolahraga-tennis.html pada tanggal 10 januari 2012, jam 10.00 WIB.

Martini FH. (2001). Fundamental of Anatomy and Physiology. USA: Prentice Hall.

Medicastore. (2010). Epikondilitis Lateralis Backhand Tennis Elbow. Diakses dari http://medicastore.com/penyakit/584/epikondilitis lateralis backhand tennis elbow.html pada tanggal 10 januari 2012, jam 12.45 WIB.

Panggung Sutapa. (2007). Upaya Pengurangan Cedera Olahraga Melalui Penguluran dan Pemanasan Sebelum Beraktivitas. Yogyakarta: FIK UNY

Ratal Ws. (1979). Kamus Lengkap Olahraga. Jakarta: CV. Baru.

Ratna Endi Yanuita, (2010). Tingkat Keberhasilan Masase Frirage dalam Cedera Lutut Ringan pada Pesilat Putri di Unit Kegiatan Mahasiswa Pencak Silat Universitas Negeri Yogyakarta. Skripsi. Yogyakarta: FIK UNY. (Hal. 71)

Taylor, P.M dan Taylor, D.K. (2002). Mencegah dan Mengatasi Cedera Olahraga. (Jamal Khalib, Terjemahan). Jakarta: RT. Grafindo Persada. Buku asli diterbitkan tahun 2002.

Tjiptosoeroso. (1983). Ilmu Lutut Olahraga. Yogyakarta: Dana P3T IKIP Yogyakarta.

(Sumber:http://www.blog.myfitnessyear.com hari selasa tanggal 5-4-2011 jam11:45)

(Sumber:http://www.footclinic.wordpress.com hari senin tanggal 04-04-2011 jam 22:15)

(Sumber:http://www.blog.myfitnessyear.com hari selasa tanggal 5-4-2011 jam11:45)

(Sumber:http://www.blog.myfitnessyear.com hari selasa tanggal 5-4-2011 jam11:53)

(sumber:http://miracleofishaholics.blogspot.com/2010/01/anatomi-dan-fisiologimanusia.html) 